\title{
Diagnostic accuracy of early urinary index changes in differentiating transient from persistent acute kidney injury in critically ill patients: multicenter cohort study
}

Bertrand Pons ${ }^{1,2}$, Alexandre Lautrette ${ }^{3,4}$, Johanna Oziel $^{5}$, Jean Dellamonica ${ }^{6}$, Régine Vermesch ${ }^{1}$, Eric Ezingeard ${ }^{1}$, Christophe Mariat 2,7, Gilles Bernardin 6,8, Fabrice Zeni ${ }^{1,2}$, Yves Cohen ${ }^{5,9}$, Bernard Tardy ${ }^{2,10,11}$, Bertrand Souweine ${ }^{3,4}$, François Vincent ${ }^{5}$ and Michael Darmon ${ }^{1,2,10^{*}}$

\begin{abstract}
Introduction: Urinary indices have limited effectiveness in separating transient acute kidney injury (AKI) from persistent AKI in ICU patients. Their time-course may vary with the mechanism of AKI. The primary objective of this study was to evaluate the diagnostic value of changes over time of the usual urinary indices in separating transient AKI from persistent AKI.

Methods: An observational prospective multicenter study was performed in six ICUs involving 244 consecutive patients, including 97 without AKI, 54 with transient AKI, and 93 with persistent AKI. Urinary sodium, urea and creatinine were measured at ICU admission ( $\mathrm{HO})$ and on 6-hour urine samples during the first $24 \mathrm{ICU}$ hours $(\mathrm{H} 6, \mathrm{H} 12$, $\mathrm{H} 18$, and H24). Transient AKI was defined as AKI with a cause for renal hypoperfusion and reversal within 3 days.

Results: Significant increases from HO to H24 were noted in fractional excretion of urea (median, 31\% (22 to 41\%) and 39\% (29 to 48\%) at H24, $P<0.0001$ ), urinary urea/plasma urea ratio (15 (7 to 28 ) and 20 (9 to 40), $P<0.0001$ ), and urinary creatinine/plasma creatinine ratio (50 (24 to 101) and 57 (29 to 104), $P=0.01$ ). Fractional excretion of sodium did not change significantly during the first 24 hours in the ICU $(P=0.13)$. Neither urinary index values at ICU admission nor changes in urinary indices between $\mathrm{HO}$ and $\mathrm{H} 24$ performed sufficiently well to recommend their use in clinical setting (area under the receiver-operating characteristic curve $\leq 0.65$ ).
\end{abstract}

Conclusion: Although urinary indices at $\mathrm{H} 24$ performed slightly better than those at $\mathrm{H} 0$ in differentiating transient AKI from persistent AKI, they remain insufficiently reliable to be clinically relevant.

\section{Introduction}

Acute kidney injury (AKI) affects approximately 5 to $30 \%$ of critically ill patients and remains associated with high mortality rates [1-3]. AKI not due to urinary tract obstruction is usually described as either transient or persistent. Transient AKI is due to low renal perfusion and is promptly reversible after normalization of the hemodynamic parameters, whereas persistent AKI is believed to be due to renal tubular damage or dysfunction [4-6].

\footnotetext{
* Correspondence: michael.darmon@chu-st-etienne.fr

'Medical ICU, Saint-Etienne University Hospital, Avenue Albert Raymond, Saint-Priest en Jarez 42270, France

Full list of author information is available at the end of the article
}

Distinguishing transient AKI from persistent AKI may help to optimize treatment decisions in patients with AKI. Urinary indices such as the fractional excretion of sodium $(\mathrm{FeNa})$ and the fractional excretion of urea (FeUrea) are believed to be reliable for separating transient AKI from persistent AKI [4,5,7-9]. However, these indices may be affected by diuretic agents or sepsis [10]. In addition, little information is available on their performance for separating transient AKI from persistent AKI in critically ill patients [11]. Urine or plasma biomarkers such as neutrophil gelatinase-associated lipocalin and IL-18 have been evaluated as tools for distinguishing between transient AKI and persistent AKI [12-15] but produced conflicting

\section{C) Biomed Central}


results and therefore cannot be recommended for widespread use at present [13,16-18].

Hemodynamic and renal perfusion changes have been shown to affect sodium excretion during the first 24 hours of sepsis in a sheep model [19]. Sepsis-associated changes in urinary indices promptly returned to normal after renal function recovery in these animals [19]. The time-course of the urinary indices may thus differ between patients with transient AKI and persistent AKI, and evaluating changes over time may therefore improve the urinary index performance in separating these two mechanisms of AKI.

The primary objective of this study was to evaluate the diagnostic value of changes over time of the usual urinary indices in separating transient AKI from persistent AKI. The secondary objectives were to evaluate the diagnostic value of the usual urinary indices at ICU admission and at 24 hours (H24) in separating transient AKI from persistent AKI.

\section{Materials and methods Patients}

The study was approved by the institutional review board of the French Society for Intensive Care Medicine (SRLF-CE-11-326), which waived the need for signed informed consent, given the observational study design. Patients and their next of kin were informed, and none refused to participate in the study.

Six university-hospital ICUs in France participated in the study between June 2011 and April 2012. Consecutive adults admitted to these ICUs were included in the absence of obstructive renal disease, renal replacement therapy (RRT) for chronic renal dysfunction, and pregnancy. Patients for whom urine could not be collected according to the study protocol were excluded secondarily; as were patients with hospital stays shorter than 72 hours, since they could not be classified as having transient AKI or persistent AKI according to our definitions.

\section{Definitions}

AKI was defined according to the Acute Kidney Injury Network classification scheme as a plasma creatinine level increase $\geq 26.4 \mu \mathrm{mol} / \mathrm{l}$, a plasma creatinine increase $\geq 150 \%$ from baseline, or urine output $<0.5 \mathrm{ml} / \mathrm{kg} / \mathrm{hour}$ for $\geq 6$ hours [20]. For patients whose baseline plasma creatinine level was unknown, this variable was estimated using either the plasma creatinine nadir during the ICU stay or, in patients who died before AKI resolution, the Modification of Diet in Renal Disease formula [6,21,22].

Transient AKI was defined as AKI with a cause of renal hypoperfusion according to the attending physician and recovery within 3 days $[6,11]$. Recovery of AKI was defined as reversal of the oliguria (in the absence of diuretic treatment) and/or $\geq 50 \%$ decrease in plasma creatinine and/or a return of plasma creatinine to the baseline value (whether measured or estimated using the Modification of Diet in Renal Disease formula) [11,23]. For patients having both oliguria and plasma creatinine changes defining AKI, both correction of plasma creatinine and oliguria were required to define recovery. Persistent AKI was defined as renal dysfunction without recovery within 3 days. Oliguria was defined as urine output $<0.5 \mathrm{ml} / \mathrm{kg} /$ hour for $\geq 6$ hours $[11,23]$.

Diuretic use at every time of this study was defined as use of diuretics in the 6 hours preceding urinary indices measurement.

Changes in urinary indices between ICU admission (H0) and $\mathrm{H} 24$ are reported as the ratio between urinary indices at $\mathrm{HO}$ by urinary indices at $\mathrm{H} 24$

\section{Data collection}

Each patient was assessed during the first 6 hours following ICU admission. Plasma sodium, urea, and creatinine levels were collected at ICU admission and then on days 1 , 2 , and 3 . Urinary sodium, potassium, urea, and creatinine were measured at $\mathrm{HO}$ and then on four consecutive 6-hour urine samples (H6, H12, H18, and H24). Urinary/ plasma (U/P) ratios were used to calculate $\mathrm{FeNa}$ and FeUrea as follow:

$$
\begin{aligned}
& \text { FeNa }(\%)=([\mathrm{U} / \text { P sodium }] /[\mathrm{U} / \text { P creatinine }]) \times 100 \\
& \text { FeUrea }(\%)=([\mathrm{U} / \text { P urea }] /[\mathrm{U} / \text { P creatinine }]) \times 100
\end{aligned}
$$

Plasma sodium, creatinine, and urea concentrations used for the calculations were those obtained closest in time to the urine sample.

The Logistic Organ Dysfunction score, the Simplified Acute Physiology Score version II and the Knaus scale score were calculated at ICU admission [24-26]. Sepsis was diagnosed using the criteria developed at the American College of Chest Physicians/Society of Critical Care Medicine consensus conference [27]. Individual organ failure was defined as a Logistic Organ Dysfunction score $>1$ point for the relevant system, except the kidney [24]. Diuretic use was defined as the use of diuretics at any time during the first 24 hours in the ICU.

\section{Statistical analysis}

Changes, as percentages, are described as the mean \pm standard deviation and other data as the median (interquartile range) or number (percentage). Categorical variables were compared using Fisher's exact test and continuous variables using the nonparametric Wilcoxon test, Mann-Whitney test, or Kruskal-Wallis test. The Friedman test was used to compare continuous variables across the three patient groups (no AKI, transient AKI, and persistent $\mathrm{AKI}$ ) and to evaluate changes in urinary index values over time. 
To assess the performance of urinary indices or their changes over the first 24 hours in distinguishing transient AKI from persistent AKI, we plotted the receiver-operating characteristic curves for the proportion of true positives against the proportion of false positives, depending on the prediction rule used to classify patients as having persistent AKI. The same strategy was used to assess the performance of indices and their changes over time in two predefined patient subgroups; namely, patients who did not receive diuretic therapy and patients without sepsis.

All tests were two-sided, and $P<0.05$ was considered statistically significant. Statistical tests were carried out using the SPSS 13 software package (IBM, Armonk, NY, USA).

\section{Results}

\section{Study population}

During the study period, 244 patients with a median age of 63 years (52 to 73 years) were included. Their main characteristics are reported in Table 1 . According to our definitions, 97 patients had no AKI (39.8\%), 54 patients (22.1\%) had transient AKI, and 93 patients (38.1\%) had persistent AKI.

At ICU admission, the median Simplified Acute Physiology Score version II was 44 (33 to 55) and the median LOD score was 5 ( 4 to 8 ). Most patients were admitted for medical conditions $(n=224,91.9 \%)$. The main risk factors for AKI were sepsis (49.8\%), exposure to contrast agents (31.1\%), diabetes mellitus (19.3\%), aminoglycoside therapy (10.2\%), and chronic kidney disease (6.1\%).

No patient was receiving RRT $t$ the time of the study. RRT was required during the ICU stay in 21 patients (8.6\%), usually during the first 24 hours in the ICU $(n=$ $14 / 244,5.7 \%)$.

\section{Urinary indices at ICU admission}

Table 1 and Figure 1 report the main urinary index values at ICU admission. Median FeNa, FeUrea, and U/P ratios of urea and creatinine differed significantly across the groups with no AKI, transient AKI, and persistent AKI.

\section{Changes in urinary indices during the first $\mathbf{2 4}$ hours after ICU admission in the overall population}

Significant increases were noted between $\mathrm{HO}$ and $\mathrm{H} 24$ in FeUrea (from 31\% (22 to $41 \%$ ) to $39 \%$ (29 to $48 \%$ ), $P<$ 0.0001 ), in U/P urea ratio (from 15 (7 to 28 ) to 20 (9 to 40 ), $P<0.0001$ ), and in U/P creatinine ratio (from 50 (24 to 101 ) to 57 (29 to 104$), P=0.01$ ) (Figure 2; Table S1 in Additional file 1$)$. FeNa did not change significantly $(P=$ 0.13 ) during the first 24 hours in the ICU.
Changes in urinary indices during the first 24 hours after ICU admission in the groups without AKI, with transient AKI, and with persistent AKI

In the group with transient AKI, FeUrea increased significantly from $\mathrm{H} 0$ to $\mathrm{H} 24$ (from $29 \%$ (21 to $39 \%$ ) to $42 \%$ (30 to $51 \%), P<0.001$ ) (Figure 2; Table S1 in Additional file 1). No significant changes in FeUrea occurred in the group with persistent AKI $(P=0.08)$. In none of the three groups did FeNa or the U/P creatinine ratio change significantly. The U/P urea ratio increased significantly in both AKI groups (transient AKI, from 11 (7 to 22) to 29 (10 to 42), $P<0.0001$; and persistent AKI, from 10 (4 to 19$)$ to 13 (6 to 27$), P<0.0001$ ).

Changes in urinary indices in patients with and without diuretic therapy are reported in Table S2 and Figures S1 and S2 in Additional file 1.

\section{Performance of urinary indices and their changes in differentiating transient from persistent acute kidney injury}

Table 2 reports the performance data for the urinary indices. None of the four urinary indices at ICU admission differentiated transient AKI from persistent AKI in the overall population (area under the receiver-operating characteristic curve 0.50 to 0.59 ) or in the subgroups without diuretic therapy or without sepsis. Compared with values at ICU admission, values at $\mathrm{H} 24$ and changes from $\mathrm{H} 0$ to $\mathrm{H} 24$ performed slightly better; however, their performance remained too poor to be clinically relevant (area under the receiver-operating characteristic curve $\leq 0.65$ for all values; Table 2 ). The main factors associated with persistent AKI after adjustment for confounders are reported in Table S3 in Additional file 1.

\section{Discussion}

To the best of our knowledge, this is the first study evaluating the time-course of standard urinary indices ( $\mathrm{FeNa}$, FeUrea, U/P urea, and U/P creatinine) in critically ill patients without AKI, with transient AKI, and with persistent AKI. The indices were not effective in differentiating transient AKI from persistent AKI. Most of them changed significantly over the first 24 hours in the ICU, but these changes did not accurately separate transient from persistent AKI.

Urinary index values at ICU admission performed poorly for differentiating transient and persistent AKI. Although many publications advocate the use of these indices, few of them focus on critically ill patients or patients with sepsis $[4,5,7,8]$. In addition, most of the available studies are single-center case series or retrospective cohort studies [28-31]. The definitions of AKI and transient AKI varied across studies, and most definitions of transient AKI relied on subjective criteria [28-31]. Finally, these studies 
Table 1 Characteristics of patients without acute kidney injury (AKI), with transient AKI, and with persistent AKI

\begin{tabular}{|c|c|c|c|c|}
\hline & No AKI $(n=97)$ & Transient AKI $(n=54)$ & Persistent AKI $(n=93)$ & $P$ value $^{a}$ \\
\hline \multicolumn{5}{|l|}{ Patient characteristics } \\
\hline Male gender & $56(57.7)$ & $34(62.9)$ & $66(71.0)$ & 0.16 \\
\hline Age (years) & 60 (49 to 70$)$ & 65 (52 to 74$)$ & 67 (56 to 76$)$ & 0.02 \\
\hline Knaus C or D & $30(30.9)$ & $18(35.3)$ & $31(36.0)$ & 0.73 \\
\hline LOD score at admission & $4(2$ to 7$)$ & 5 (3 to 8$)$ & $6(4$ to 9$)$ & 0.006 \\
\hline SAPS II score at admission & 41 (31 to 54 ) & 43 (34 to 52) & 46 (36 to 59$)$ & 0.06 \\
\hline Baseline plasma creatinine ( $\mu \mathrm{mol} / \mathrm{l})$ & 55 (45 to 65$)$ & 56 (44 to 69$)$ & 65 (53 to 89) & 0.0006 \\
\hline \multicolumn{5}{|l|}{ Risk factors for $\mathrm{AKI}$} \\
\hline Chronic heart failure & $11(11.3)$ & $11(20.3)$ & $18(19.4)$ & 0.22 \\
\hline Chronic kidney disease $^{\mathrm{b}}$ & $2(2.1)$ & $1(1.9)$ & $12(12.9)$ & 0.02 \\
\hline Sepsis & $36(38.7)$ & $32(60.4)$ & $48(55.2)$ & 0.02 \\
\hline Aminoglycosides & $6(6.7)$ & $7(14.6)$ & $12(14.0)$ & 0.22 \\
\hline lonidated contrast agents & $37(41.1)$ & $11(22.9)$ & $22(25.3)$ & 0.03 \\
\hline Diabetes mellitus & $8(8.3)$ & $15(27.8)$ & $24(25.8)$ & 0.002 \\
\hline \multicolumn{5}{|l|}{ Reason for ICU admission } \\
\hline Acute respiratory failure & $24(24.7)$ & $17(31.5)$ & $19(20.5)$ & 0.32 \\
\hline Coma & $36(37.1)$ & $8(14.8)$ & $15(16.1)$ & 0.0006 \\
\hline Sepsis/shock & $13(13.4)$ & $19(35.2)$ & $43(46.3)$ & $<0.0001$ \\
\hline \multicolumn{5}{|l|}{ Treatments } \\
\hline Need for vasoactive drugs & $80(51.6)$ & $25(46.3)$ & $55(59.1)$ & 0.29 \\
\hline Mechanical ventilation & 79 (81.4) & $30(55.6)$ & $55(59.4)$ & 0.0006 \\
\hline Renal replacement therapy & $1(1.0)$ & 0 & $13(14.0)$ & $<0.0001$ \\
\hline Diuretics & $30(30.9)$ & $17(31.5)$ & $33(35.5)$ & 0.78 \\
\hline \multicolumn{5}{|l|}{ Renal function at admission } \\
\hline Diuresis (ml/kg/hour) & 1.29 (0.69 to 1.99$)$ & 1.14 (0.73 to 2.00$)$ & 0.79 (0.48 to 1.22$)$ & 0.0005 \\
\hline Plasma urea (mmol/l) & $5.9(4.4$ to 8.1$)$ & $10.8(7.3$ to 14.9$)$ & 14.1 (7.6 to 25.2$)$ & $<0.0001$ \\
\hline Plasma creatinine $(\mu \mathrm{mol} / \mathrm{l})$ & 64 (53 to 80) & 111 (76 to 170$)$ & 139 (95 to 253$)$ & $<0.0001$ \\
\hline \multicolumn{5}{|l|}{ Urinary indices } \\
\hline FeNa (\%) & $0.7(0.2$ to 1.7$)$ & 0.8 (0.3 to 2.7$)$ & 1.1 (0.4 to 2.8 ) & 0.03 \\
\hline FeUrea (\%) & 35 (24 to 45$)$ & 29 (21 to 39$)$ & 29 (21 to 36$)$ & 0.03 \\
\hline U/P urea & 23 (14 to 34$)$ & 11 (7 to 22$)$ & 10 (4 to 19$)$ & $<0.0001$ \\
\hline U/P creatinine & 70 (39 to 129) & 37 (17 to 98) & 38 (17 to 74$)$ & $<0.0001$ \\
\hline \multicolumn{5}{|l|}{ Outcome } \\
\hline ICU mortality & $22(22.7)$ & $12(22.2)$ & $21(22.5)$ & 0.99 \\
\hline Hospital mortality & $25(25.8)$ & $17(31.5)$ & $26(28.0)$ & 0.56 \\
\hline
\end{tabular}

Results reported as median (interquartile range) or $n$ (\%). FeNa, fractional excretion of sodium ([U/P sodium]/[U/P creatinine]) $\times 100$; FeUrea, fractional excretion of urea ([U/P urea]/[U/P creatinine]) $\times 100 ;$ LOD, Logistic Organ Dysfunction score (can range from 0 to 22); SAPS, Simplified Acute Physiology Score; U/P, urinary/plasma. ${ }^{\mathrm{a}} \mathrm{P}$ values are for comparisons across the three patient groups. ${ }^{\mathrm{b}} \mathrm{Chronic}$ renal failure was defined as creatinine clearance before ICU admission $<60 \mathrm{ml} /$ minute. Bold data represent variables that differ statistically across groups of patients.

included patients who did not have critical illnesses $[9,31,32]$. In our study, we used an objective definition of transient AKI. Most of the study patients had sepsis at ICU admission, a condition associated with alterations in renal handling of sodium and water despite normal renal perfusion or adequate fluid therapy [19]. This point may explain the differences between our results and those of previous studies [9,28,30-32]. Interestingly, $\mathrm{FeNa}$ and FeUrea were usually decreased in both transient AKI and persistent AKI $[11,19]$, suggesting partial preservation of tubular function even in patients with persistent AKI $[19,23]$. In critically ill patients, therefore, urinary indices may be unable to distinguish transient AKI from persistent AKI.

The main objective of this study was to evaluate the diagnostic performance of urinary index changes over the first 24 hours in the ICU for separating transient AKI and persistent AKI. In sheep, FeNa declined within the first few hours after the induction of septic AKI and then returned to normal during renal recovery [19]. Similarly, urinary indices returned to normal within 24 hours in our patients, and the improvement was more rapid in the transient AKI group than in the persistent AKI group. As a result, $\mathrm{H} 24$ values performed significantly better than 
1a.

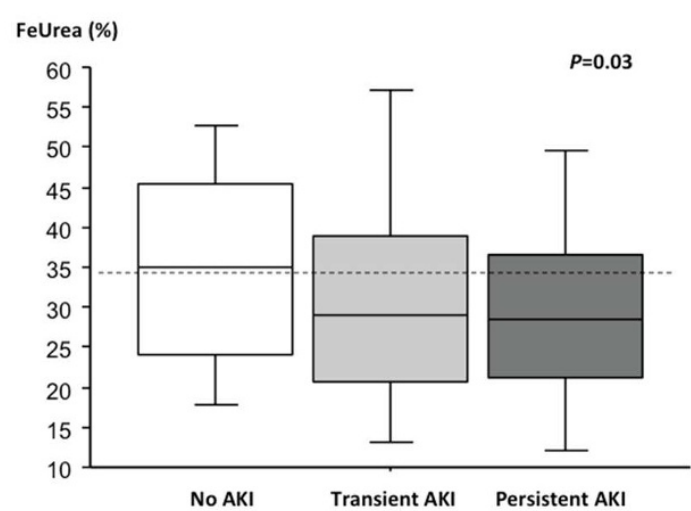

1c.

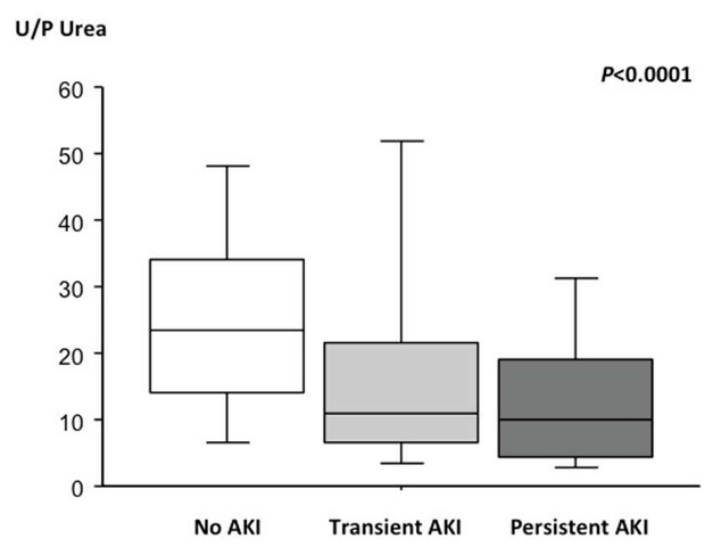

$1 b$.

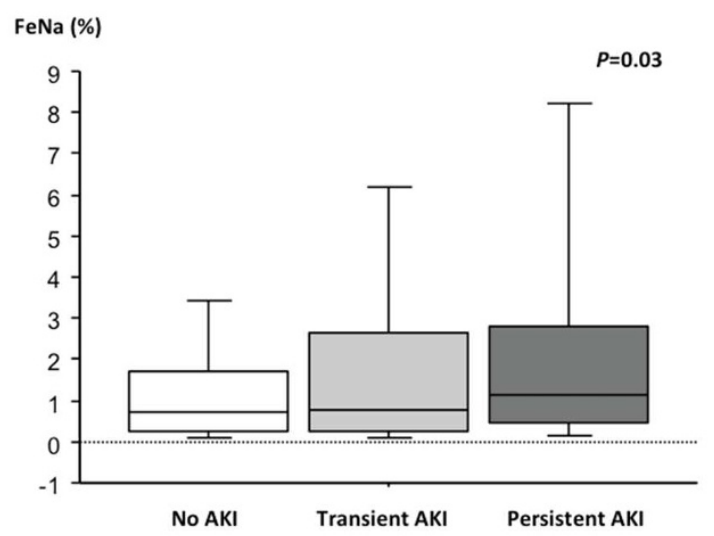

$1 d$.

U/P Creatinine

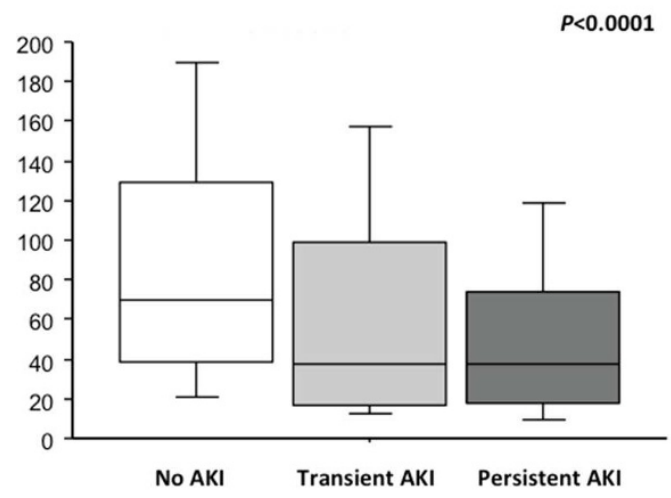

Figure 1 Boxplot representation of urinary indices at baseline according to renal function. (a) Fractional excretion of urea (FeUrea) according to renal function $(P=0.03)$. (b) Fractional excretion of sodium (FeNa) according to renal function $(P=0.03)$. (c) The urine/plasma (U/ P) urea ratio according to renal function $(P<0.0001)$. (d) The U/P creatinine ratio according to renal function $(P<0.0001)$. AKl, acute kidney injury. Whiskers represent 5 th to 95 th percentiles.

$\mathrm{HO}$ values in differentiating transient AKI from persistent AKI. Nevertheless, performance of the H24 values remained too low to be clinically relevant.

Interestingly, diuretic therapy had no effect on urinary indices or their changes over time in our study. In particular, FeNa changes over the first 24 hours were not significantly different in the groups with and without diuretic therapy. Resistance to diuretics may explain this finding. Heart failure, renal hypoperfusion related to shock or sepsis, and hypoalbuminemia are common in ICU patients and can result in resistance to diuretics $[33,34]$. In patients given diuretics before ICU admission, rebound sodium retention, a post-diuretic effect, and diuretic braking also contribute to diuretic resistance $[35,36]$. Last, our patients received diuretics as bolus injections. Using continuous infusions [37,38] or higher dosages might have produced different results.
Our study has several limitations. First, our definition of transient AKI was based on renal function recovery. Indeed, a more selective definition of pre-renal AKI would have required the use of highly subjective criteria such as clinical history, physical examination, and physician judgment $[9,10]$. We elected to use a definition that relied on an objective criterion. In addition, our definition takes into account the continuum that probably exists between renal hypoperfusion and kidney damage [6]. The difference between our definition of transient AKI and that used in earlier studies may contribute to the discrepancies in the results. Moreover, our definition was highly sensitive for detecting patients with transient AKI, since none of these patients required RRT, but also lacked specificity, as less than $20 \%$ of patients with persistent AKI required RRT. This limitation must be taken into account when interpreting our results. In addition, 
2a.

FeUrea (\%)

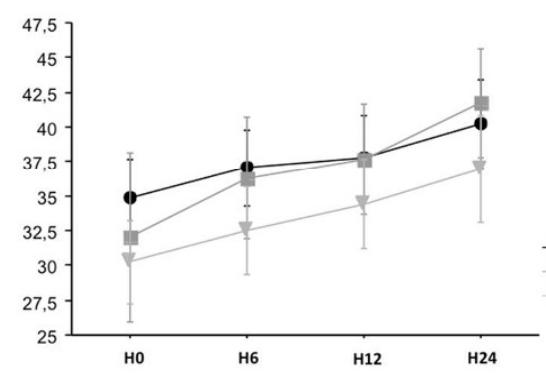

No AKI $(P=0.01)$

AKI $(P<0.001)$

Persistent AKI $(P=0.08)$
$2 b$.

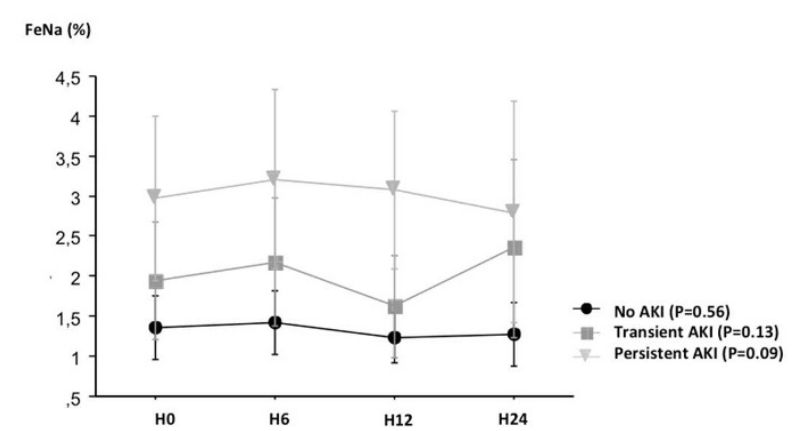

2c.

U/P Urea

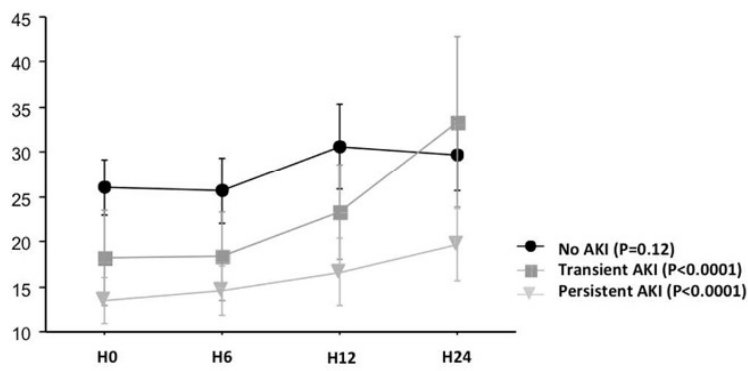

$2 d$.

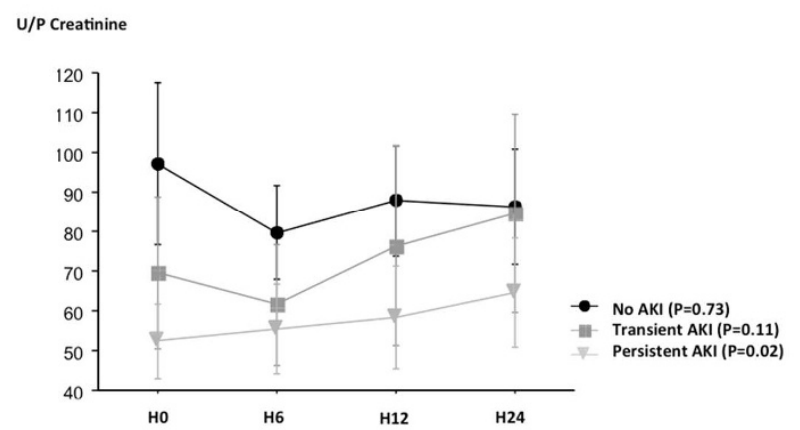

Figure $\mathbf{2}$ Changes in urinary indices during the first $\mathbf{2 4}$ hours after ICU admission according to renal function. (a) Fractional excretion of urea (FeUrea) according to renal function. (b) Fractional excretion of sodium (FeNa) according to renal function. (c) The urine/plasma (U/P) urea ratio according to renal function. (d) The U/P creatinine ratio according to renal function. AKl, acute kidney injury; H0, ICU admission; H6, H12, $\mathrm{H} 18$, and H24, 6-hour urine samples during the first 24 ICU hours. Data presented as mean $\pm 95 \%$ confidence interval.

Table 2 Diagnostic performance of and changes in urinary indices at ICU admission and after 24 hours

\begin{tabular}{|c|c|c|c|}
\hline Patients with AKI & Overall population $(n=147)$ & Patients without diuretics $(n=97)$ & Patients without sepsis $(n=60)$ \\
\hline \multicolumn{4}{|c|}{ Urinary indices at ICU admission } \\
\hline FeNa & 0.59 (0.49 to 0.69$)$ & 0.54 (0.41 to 0.66$)$ & 0.59 (0.42 to 0.75$)$ \\
\hline FeUrea & 0.50 (0.41 to 0.60$)$ & 0.53 (0.41 to 0.65$)$ & 0.64 (0.49 to 0.79$)$ \\
\hline U/P urea & 0.57 (0.48 to 0.67$)$ & 0.56 (0.45 to 0.68$)$ & 0.59 (0.45 to 0.74$)$ \\
\hline U/P creatinine & 0.55 (0.45 to 0.65$)$ & 0.53 (0.41 to 0.65$)$ & 0.61 (0.46 to 0.77$)$ \\
\hline \multicolumn{4}{|c|}{ Urinary indices at $\mathrm{H} 24$} \\
\hline FeNa & $0.61(0.51$ to 0.71$)$ & $0.64(0,52 \text { to } 0,76)^{*}$ & $0,56(0,40$ to 0.72$)$ \\
\hline FeUrea & 0.51 (0.40 to 0.62$)$ & 0.57 (0.43 to 0.70$)$ & $0.56(0.39$ to 0.72$)$ \\
\hline U/P urea & $0.65(0.55 \text { to } 0.75)^{*}$ & $0.65(0.53 \text { to } 0.76)^{*}$ & $0.67(0.51 \text { to } 0.83)^{*}$ \\
\hline U/P creatinine & 0.58 (0.48 to 0.69$)$ & $0.56(0.43$ to 0.69$)$ & $0.58(0.41$ to 0.76$)$ \\
\hline \multicolumn{4}{|c|}{ Changes in urinary indices between $\mathrm{H} 0$ and $\mathrm{H} 24$} \\
\hline FeNa & 0.59 (0.49 to 0.70$)$ & 0.58 (0.45 to 0.71$)$ & $0,59(0,40$ to 0.78$)$ \\
\hline FeUrea & $0.57(0.47 \text { to } 0.68)^{*}$ & 0.58 (0.44 to 0.72 ) & 0.61 (0.43 to 0.78$)$ \\
\hline U/P urea & $0.61(0.51 \text { to } 0.71)^{*}$ & 0.60 (0.47 to 0.73$)$ & 0.65 (0.48 to 0.81$)$ \\
\hline U/P creatinine & 0.51 (0.49 to 0.62$)$ & 0.52 (0.40 to 0.65$)$ & 0.53 (0.33 to 0.70$)$ \\
\hline
\end{tabular}

Diagnostic performance of urinary indices at ICU admission and after 24 hours, and changes in urinary indices over the first 24 hours in the ICU for separating transient from persistent acute kidney injury. Data are areas under the receiver-operating characteristic curves ( $\pm 95 \%)$. AKI, acute kidney injury; FeNa, fractional excretion of sodium ([U/P sodium]/[U/P creatinine]) $\times 100$; FeUrea, fractional excretion of urea ([U/P urea]/[U/P creatinine]) $\times 100 ; \mathrm{H0}, \mathrm{ICU}$ admission; H24, 24 hours; $\mathrm{U} / \mathrm{P}$, urinary/plasma. ${ }^{*} P<0.05$. Bold data represent AUC that differ statistically from 0.5 . 
an imbalance of the case mix across the three groups of patients (no AKI, transient AKI and persistent AKI) was observed. Patients without AKI were thus more frequently admitted for neurological dysfunction than patients with AKI usually admitted with severe sepsis or septic shock. This may explain the higher rate of mechanical ventilation in patients without AKI than patients with AKI and the absence of association between mortality and AKI in this study. However, performance of urinary indices in this study is consistent with previous studies performed in different ICUs or in populations with a different case mix $[11,15]$. Another limit of our study was that neither fluid balance nor fluid therapy was recorded. We may suppose that both these variables could influence the final results.

Although our study suggests that none of the usual urinary indices or their changes may reliably help in distinguishing transient AKI from persistent AKI, further studies are needed to assess influence of fluid challenge and fluid balance on urinary index course or performance. Last, we did not evaluate newly described biomarkers for diagnosing transient AKI. Future studies should compare these biomarkers with the standard urinary indices evaluated in our study.

\section{Conclusion}

This study confirms the poor performance of standard urinary indices at ICU admission for differentiating transient AKI from persistent AKI in unselected critically ill patients. Although changes over the first 24 hours and values at $\mathrm{H} 24$ performed slightly better than values at admission, their performance remained too low to be clinically useful. Additional studies are needed to identify means of reliably separating transient and persistent AKI, with the goal of improving early therapeutic interventions.

\section{Key messages}

- Standard urinary index values at ICU admission performed poorly for differentiating transient AKI and persistent AKI.

- Although changes over the first 24 hours and values at $\mathrm{H} 24$ performed slightly better than values at admission, their performance remained too low to be clinically useful.

- Performance of newest biomarkers in this setting remains to be evaluated.

\section{Additional material}

Additional file 1: Table S1 showing changes in urinary indices during the first $\mathbf{2 4}$ hours following ICU admission and Table S2 showing the influence of diuretic therapy. Table S3 showing factors independently associated with persistent AKI in a conditional logistic regression model. Figure S1 showing changes in urinary indices in the overall population, in patients receiving diuretic therapy during the first
24 hours following ICU admission and in patients without diuretic therapy. Figure S2 showing change in urinary indices according to renal function and use of diuretics.

\section{Abbreviations}

AKI: acute kidney injury; FeNa: fractional excretion of sodium; FeUrea: fractional excretion of urea; RRT: renal replacement therapy; U/P: urinary/ plasma.

\section{Authors' contributions}

BP participated in the study concept and design, acquisition of data, analysis and interpretation of data, drafting of the manuscript and critical revision of the manuscript. AL participated in the study design, acquisition of data, analysis and interpretation of data, drafting of the manuscript and critical revision of the manuscript. JO, JD, RV, EE, CM, GB, FZ, YC and BT participated in acquisition of data, interpretation of data, and critical revision of the manuscript. BS and FV participated in the study design, acquisition of data, analysis and interpretation of data, drafting of the manuscript and critical revision of the manuscript. MD conceived the study, participated in study design and coordination, acquisition of data, statistical analysis and interpretation of data, drafting of the manuscript and critical revision of the manuscript. MD had full access to all of the data in the study and takes responsibility for the integrity of the data and the accuracy of the data analysis. All authors read and approved the final manuscript.

\section{Competing interests}

The authors declare that they have no competing interests.

\section{Acknowledgements}

The authors thank A Wolfe MD for help with this manuscript. This study was supported by a grant from Saint-Etienne University Hospital. This study was carried out in the following six ICUs: Saint-Etienne University Hospital, Saint Etienne, France (three ICUs); Clermont-Ferrand University Hospital, ClermontFerrand, France; Archet University Hospital, Nice, France; and Avicenne University Hospital, Bobigny, France.

\section{Author details}

'Medical ICU, Saint-Etienne University Hospital, Avenue Albert Raymond, Saint-Priest en Jarez 42270, France. ${ }^{2}$ Jacques Lisfranc Medical School, SaintEtienne University, 15 Rue Ambroise Paré, Saint-Etienne 42000, France. ${ }^{3}$ Medical ICU, Gabriel Montpied University Hospital, 58 Rue Montalembert, 63003 Clermont Ferrand cedex 1, France. ${ }^{4}$ Clermont-Ferrand Medical School, Auvergne University, 28 place Henri-Dunant BP 38, 63001 Clermont-Ferrand cedex 1, France. ${ }^{5}$ Medical-Surgical Intensive Care Unit, Avicenne University Hospital, APHP, 125 rue de Stalingrad, Bobigny 93009, France. ${ }^{6}$ Medical Intensive Care Unit, Archet University Hospital, 151 Rte Saint Antoine Ginestiere, Nice 06202, France. ${ }^{7}$ Nephrology, Dialysis and Renal Transplantation, Saint-Etienne University Hospital, Avenue Albert Raymond, Saint-Priest en Jarez 42270, France. ${ }^{8}$ Nice University, UFR de Médecine, 28 Avenue de Valombrose, 06107 NICE cedex 2, France. ${ }^{9}$ Bobigny Medical School, Paris-13 University, 74 rue Marcel Cachin, 93017 Bobigny cedex, France. ${ }^{10}$ Thrombosis Research Group, EA 3065, Saint-Etienne University Hospital, Avenue Albert Raymond, Saint-Priest en Jarez 42270, France.

${ }^{11}$ Department of Emergency Medicine, Saint-Etienne University Hospital, Avenue Albert Raymond, Saint-Priest en Jarez 42270, France.

Received: 31 December 2012 Revised: 15 February 2013 Accepted: 21 March 2013 Published: 26 March 2013

\section{References}

1. Brivet $F G$, Kleinknecht $D J$, Loirat $P$, Landais $P J:$ Acute renal failure in intensive care units - causes, outcome, and prognostic factors of hospital mortality; a prospective, multicenter study. French Study Group on Acute Renal Failure. Crit Care Med 1996, 24:192-198.

2. Metnitz PGH, Krenn CG, Steltzer H, Lang T, Ploder J, Lenz K, Le Gall J-R, Druml W: Effect of acute renal failure requiring renal replacement therapy on outcome in critically ill patients. Crit Care Med 2002, 30:2051-2058. 
3. Bagshaw SM: Short- and long-term survival after acute kidney injury. Nephrol Dial Transplant 2008, 23:2126-2128.

4. Lameire N, Van Biesen W, Vanholder R: Acute kidney injury. Lancet 2008, 372:1863-1865.

5. Schrier RW, Wang W, Poole B, Mitra A: Acute renal failure: definitions, diagnosis, pathogenesis, and therapy. J Clin Invest 2004, 114:5-14.

6. Khwaja A: KDIGO clinical practice guidelines for acute kidney injury. Nephron Clin Pract 2012, 120:179-184.

7. Espinel $\mathrm{CH}$ : The FENa test. Use in the differential diagnosis of acute renal failure. JAMA 1976, 236:579-581.

8. Miller TR, Anderson RJ, Linas SL, Henrich WL, Berns AS, Gabow PA Schrier RW: Urinary diagnostic indices in acute renal failure: a prospective study. Ann Intern Med 1978, 89:47-50.

9. Carvounis CP, Nisar S, Guro-Razuman S: Significance of the fractional excretion of urea in the differential diagnosis of acute renal failure. Kidney Int 2002, 62:2223-2229.

10. Bagshaw SM, Langenberg C, Bellomo R: Urinary biochemistry and microscopy in septic acute renal failure: a systematic review. Am J Kidney Dis 2006, 48:695-705.

11. Darmon M, Vincent F, Dellamonica J, Schortgen F, Gonzalez F, Das V, Zeni F, Brochard L, Bernardin G, Cohen Y, Schlemmer B: Diagnostic performance of fractional excretion of urea in the evaluation of critically ill patients with acute kidney injury: a multicenter cohort study. Crit Care 2011, 15:R178

12. Bagshaw SM, Bennett M, Haase M, Haase-Fielitz A, Egi M, Morimatsu H, D'amico G, Goldsmith D, Devarajan P, Bellomo R: Plasma and urine neutrophil gelatinase-associated lipocalin in septic versus non-septic acute kidney injury in critical illness. Intensive Care Med 2010, 36:452-461.

13. Nickolas TL, O'Rourke MJ, Yang J, Sise ME, Canetta PA, Barasch N, Buchen C, Khan F, Mori K, Giglio J, Devarajan P, Barasch J: Sensitivity and specificity of a single emergency department measurement of urinary neutrophil gelatinase-associated lipocalin for diagnosing acute kidney injury. Ann Intern Med 2008, 148:810-819.

14. Parikh CR, Mishra J, Thiessen-Philbrook H, Dursun B, Ma Q, Kelly C, Dent C Devarajan P, Edelstein CL: Urinary IL-18 is an early predictive biomarker of acute kidney injury after cardiac surgery. Kidney Int 2006, 70:199-203.

15. Bagshaw SM, Bennett M, Devarajan P, Bellomo R: Urine biochemistry in septic and non-septic acute kidney injury: a prospective observational study. J Crit Care 2012

16. Nejat M, Pickering JW, Devarajan P, Bonventre JV, Edelstein CL, Walker RJ, Endre ZH: Some biomarkers of acute kidney injury are increased in prerenal acute injury. Kidney Int 2012, 81:1254-1262.

17. Doi K, Negishi K, Ishizu T, Katagiri D, Fujita T, Matsubara T, Yahagi N, Sugaya T, Noiri E: Evaluation of new acute kidney injury biomarkers in a mixed intensive care unit. Crit Care Med 2011, 39:2464-2469.

18. Siew ED, Ware LB, Ikizler TA: Biological markers of acute kidney injury. J Am Soc Nephrol 2011, 22:810-820.

19. Langenberg C, Wan L, Egi M, May CN, Bellomo R: Renal blood flow and function during recovery from experimental septic acute kidney injury. Intensive Care Med 2007, 33:1614-1618.

20. Mehta RL, Kellum JA, Shah SV, Molitoris BA, Ronco C, Warnock DG, Levin A: Acute Kidney Injury Network: report of an initiative to improve outcomes in acute kidney injury. Crit Care 2007, 11:R31.

21. Bellomo R, Ronco C, Kellum JA, Mehta RL, Palevsky P: Acute renal failure definition, outcome measures, animal models, fluid therapy and information technology needs: the Second International Consensus Conference of the Acute Dialysis Quality Initiative (ADQI) Group. Crit Care 2004, 8:R204-R212.

22. Závada J, Hoste E, Cartin-Ceba R, Calzavacca P, Gajic O, Clermont G, Bellomo R, Kellum JA: A comparison of three methods to estimate baseline creatinine for RIFLE classification. Nephrol Dial Transplant 2010, 25:3911-3918.

23. Darmon M, Schortgen F, Vargas F, Liazydi A, Schlemmer B, Brun-Buisson C, Brochard L: Diagnostic accuracy of Doppler renal resistive index for reversibility of acute kidney injury in critically ill patients. Intensive Care Med 2011, 37:68-76.

24. Le Gall JR, Klar J, Lemeshow S, Saulnier F, Alberti C, Artigas A, Teres D: The Logistic Organ Dysfunction system. A new way to assess organ dysfunction in the intensive care unit. ICU Scoring Group. JAMA 1996 276:802-810.
25. Le Gall JR, Lemeshow S, Saulnier F: A new Simplified Acute Physiology Score (SAPS II) based on a European/North American multicenter study. JAMA 1993, 270:2957-2963.

26. Knaus WA, Draper EA, Wagner DP, Zimmerman JE: APACHE II: a severity of disease classification system. Crit Care Med 1985, 13:818-829.

27. Levy MM, Fink MP, Marshall JC, Abraham E, Angus D, Cook D, Cohen J, Opal SM, Vincent J-L, Ramsay G: 2001 SCCM/ESICM/ACCP/ATS/SIS International Sepsis Definitions Conference. Intensive Care Med 2003, 29:530-538.

28. Diamond JR, Yoburn DC: Nonoliguric acute renal failure associated with a low fractional excretion of sodium. Ann Intern Med 1982, 96:597-600.

29. Hilton PJ, Jones NF, Barraclough MA, Lloyd-Davies RW: Urinary osmolality in acute renal failure due to glomerulonephritis. Lancet 1969, 2:655-656.

30. Lam M, Kaufman CE: Fractional excretion of sodium as a guide to volume depletion during recovery from acute renal failure. Am J Kidney Dis 1985, 6:18-21.

31. Tungsanga $K$, Boonwichit $D$, Lekhakula $A$, Sitprija V: Urine uric acid and urine creatine ratio in acute renal failure. Arch Intern Med 1984, 144:934-937.

32. Pépin M-N, Bouchard J, Legault L, Ethier J: Diagnostic performance of fractional excretion of urea and fractional excretion of sodium in the evaluations of patients with acute kidney injury with or without diuretic treatment. Am J Kidney Dis 2007, 50:566-573.

33. Wilcox CS, Mitch WE, Kelly RA, Skorecki K, Meyer TW, Friedman PA, Souney PF: Response of the kidney to furosemide. I. Effects of salt intake and renal compensation. J Lab Clin Med 1983, 102:450-458.

34. Vasko MR, Cartwright DB, Knochel JP, Nixon JV, Brater DC: Furosemide absorption altered in decompensated congestive heart failure. Ann Intern Med 1985, 102:314-318.

35. Asare K: Management of loop diuretic resistance in the intensive care unit. Am J Health Syst Pharm 2009, 66:1635-1640.

36. Brater DC: Diuretic therapy. N Engl J Med 1998, 339:387-395.

37. Lahav M, Regev A, Ra'anani P, Theodor E: Intermittent administration of furosemide vs continuous infusion preceded by a loading dose for congestive heart failure. Chest 1992, 102:725-731.

38. Dormans TP, Van Meyel JJ, Gerlag PG, Tan Y, Russel FG, Smits P: Diuretic efficacy of high dose furosemide in severe heart failure: bolus injection versus continuous infusion. J Am Coll Cardiol 1996, 28:376-382.

doi:10.1186/cc12582

Cite this article as: Pons et al:: Diagnostic accuracy of early urinary index changes in differentiating transient from persistent acute kidney injury in critically ill patients: multicenter cohort study. Critical Care 2013 17:R56.

\section{Submit your next manuscript to BioMed Central and take full advantage of:}

- Convenient online submission

- Thorough peer review

- No space constraints or color figure charges

- Immediate publication on acceptance

- Inclusion in PubMed, CAS, Scopus and Google Scholar

- Research which is freely available for redistribution

Submit your manuscript at www.biomedcentral.com/submit
C Biomed Central 